\title{
Adolescents' Predictions of Aggressive Behavioral Patterns in Different Settings
}

\author{
María de la Paz Toldos Romero* \\ Escuela de Negocios y Humanidades. Tecnológico de Monterrey, Campus Guadalajara, Jalisco (México), Avda. \\ General Ramón Corona 2514 (Col. Nuevo México), 45201 Zapopan, Jal. México
}

\begin{abstract}
Few studies have examined adolescents' predictions of aggression involving other adolescents; previous research has focused mainly on studying the perceptions of physical aggression. Therefore, the aim of this study is to explore adolescents' predictions of physical, verbal, and indirect aggression in hypothetical scenarios of aggression and to establish any sex differences in these predictions. A total of 653 adolescents aged 14 to 18 participated in the study. The sex of the aggressor and the sex of the target were manipulated, and participants' predictions of the likelihood of aggressive behavioral patterns were measured through the use of a questionnaire. Results showed a significant interaction between the two independent variables. More specifically, results showed that (i) when the aggressor and the target were both males, the subjects more often predicted that the aggressor would use physical and verbal aggression; (ii) when the aggressor and the target were both females, subjects predicted that the aggressor would use more indirect aggression; (iii) males predicted the use of physical aggression more readily when the target was a male; (iv) females predicted the use of verbal and indirect aggression more readily than males when the target was a female; and (v) the situations in which subjects predicted that the aggressor would use more physical, verbal and indirect aggression were when the aggression took place between peers, followed by situations in which aggression took place in a domestic context.
\end{abstract}

Keywords: Physical aggression, verbal aggression, indirect aggression, prediction.

\section{INTRODUCTION}

Many studies in research on aggression have established a classification of various types of aggression in terms of its form and behavior [e.g., 1-5]. Moreover, there is a significant amount of research looking at sex differences in different types of aggressive behavior [e.g., 6-15]. However, differences in aggressiveness between men and women are often small and inconsistent [16-18]. It has often been suggested that males are in general more physically aggressive than females [18-21]. For verbal aggression, some researchers have found that the sex differences tend to be in the same direction, but are smaller and less consistent [16, 18, 22, 23], while others have found that females prefer to use more verbal aggression than males [e.g., 24, 25]. Indirect aggression was originally defined as "a type of behavior in which the perpetrator attempts to inflict pain in such a manner that he or she (often) makes it seem as though there has been no intention to hurt at all" [26], and was distinguished from direct aggression, characterized by "straightforward attacks that are often visible, disruptive, and frightening even to the spectators" [27]. Therefore, indirect aggression, which included such acts as gossiping, spreading rumors, or excluding someone from the group, was suggested to be more typical of females than of males [1, 3, 6-8, 26, 28-39]. Archer's

\footnotetext{
*Address correspondence to this author at the Escuela de Negocios y Humanidades. Tecnológico de Monterrey, Campus Guadalajara, Jalisco (México), Avda. General Ramón Corona 2514 (Col. Nuevo México), 45201 Zapopan, Jal. México; Tel: +54- (33) 36693000 (Ext. 2260);

Fax: +54- (33) 36693000 (Ext.2256);

E-mails: mariadelapaz.toldos@itesm.mx,paztoldos@hotmail.com
}

[6] meta-analysis revealed that girls use slightly more indirect aggression than boys; however, this effect is very small and appears to be dependent on the age of the participant and the elicitation method. Any sex differences that do exist appear to be greatest in late childhood to early adolescence, and gradually taper off in adulthood [6]. In any case, the use of indirect aggression rather than physical aggression is more socially acceptable in the "girl world" because this type of behavior is consistent with the female gender role, whereas physical aggression is more closely linked to the male gender role $[40,41]$.

Furthermore, there is a significant amount of research looking at the perceptions of aggressive interactions between males and females and how they are perceived differently by observers. These studies have examined the effects of the sex of the target and the aggressor on perceptions, seriousness, attributions, and assessments of the aggressive behavior in real or hypothetical situations. Some research found diverse results as a function of the variables used in the study [42]. For example, in some studies the researchers arranged the observation so that observers were unable to decipher the sex of the aggressor and the target. In some of these studies the results indicated that when the sex was unknown, the subjects viewed the aggression between two boys as the least aggressive, as their behavior was more likely to be attributed to rough-and-tumble play than to intentional harm. However, the subjects viewed such behavior by girls as aggression rather than as play [43]. On the other hand, in similar studies the sex of the children was made clear to observers, and when the sex of the aggressor and the target was known, subjects rated boys and girls as equally aggressive; neverthe- 
less, boys' aggression was seen as more intentional and masculine $[44,45]$.

Research in gender stereotypes has shown that violent situations between males and females are perceived differently by observers. Generally males are perceived to be more aggressive than females [46-48] and people perceive greater aggression when the target is a female. These findings are supported by research. For example, in one study carried out by Gerber [49] the conclusions showed that the male aggressor was perceived to be physically more aggressive than the female aggressor. In another study, Harris and KnightBohnhoff [50] manipulated the sex of the aggressor and the sex of the target across experimental groups using sequences of vignettes that described aggressive interactions to explore whether these variables affected the perception of aggressive behavior. They found that participants perceived the act to be more aggressive when the aggressor was a male. In another study, participants saw aggressions greater when carried out by males than if the same aggressive acts were carried out by females [51]. Hilton et al. [52] found that when the sex of the perpetrator and the sex of the victim were manipulated in scenarios depicting either sexual or nonsexual physical aggression, sexual aggression was rated as more serious than nonsexual physical aggression, especially when involving physical force, and male-to-female aggression was rated as most serious while male-to-male aggression was perceived as least serious. In a study carried out by Steward-Williams [53], participants of both sexes rated women's aggression as more acceptable than men's aggression; male participants considered women's aggression more acceptable, apparently because they saw the act as less aggressive. In a study by Marks and Nelson [54], the sex of the initiator of the behavior and the type of behavior was manipulated, and the results showed that the behavior of female professors who initiated sexual harassment behavior toward male students was perceived as more appropriate than the same behavior initiated by male professors toward female students in identical situations. In experiments on the perception of parental discipline, researchers found that when a father punished his child, the punishment was rated harsher than when the disciplinarian was the mother $[55,56]$. As for research on direct and indirect aggression, Lutz [57] found that direct aggressive behaviors, especially verbal aggression, were perceived to be more effective and more likely to happen than other types of aggression; in this case physical aggression was perceived to be more aggressive, more effective, and more likely for males than for females. On the other hand, indirect aggressive behaviors were considered to be less effective, less aggressive and less likely than direct aggressive behaviors, although more appropriate and effective when a female used them. A study about secondary high school teachers' perceptions of adolescent female social aggression concluded that high school teachers perceived overt negative behaviors on the part of adolescent females to constitute female relational social aggression; the study also found the primary form of indirect aggression that females engaged in was rumor spreading [58]. Specific to dating violence, Sears et al. [59] found that adolescents perceive males as engaging in physical abuse more frequently than females, and females as engaging in psychological abuse more frequently than their male counterparts, primarily as a result of gender expectations regarding appropriate responses to stressful situations. Basow et al. [60] found that college students rated indirect aggression by women and physical aggression by men as less acceptable and more aggressive than the same behavior by the other sex. Thus, expectations regarding the sexappropriateness of aggression appear to affect perceptions of such acts.

Research has also indicated that males and females differ in their perceptions and evaluation of aggressive behavior. For example, a study carried out by Lyons and Serbin [61] found that subjects of both sexes rated male aggression as more aggressive than female aggression. Eagly and Steffen [16] found that both sexes perceived females as less likely than males to act aggressively. On average, female observers see greater levels of aggression than males do [50, 51, 55]. Authors such as García et al. [62] found that males perceived an incident of aggression to be more aggressive when the target was a female, while females perceived the incident to be more aggressive when the target was a male. Also, in a study on sexual harassment between professors and students, Marks and Nelson [54] found that females perceived the behavior as harassment and as inappropriate more often than males did, although some types of harassment were interpreted by females as more appropriate than when these same types were interpreted by males. In a domestic context, Koski and Mangold [63] found that females perceived domestic aggression as a more serious behavior than males did, and both sexes considered aggression by a female to be more acceptable than aggression by a male. In this same line, Harris and Cook [64] found that schoolgirls considered an aggressive incident much more violent than boys did, and that the mistreatment of a wife was more serious than the same incident in which the target was a husband. They also found that women sympathized more with the target despite the similarity between the target and the aggressor. Harris and Knight-Bohnhoff [50] also found that women considered incidents of aggression much more serious than men did. When Galen and Underwood [65] showed examples of reallife social aggression to a group of adolescents, girls rated the aggressors as angrier than boys did. Hilton et al. [52] found in scenarios depicting sexual aggression that girls gave a higher seriousness rating to sexual aggression involving physical force than did boys.

All of these studies, to cite only a few, support the idea that violent situations between men and women are perceived differently by observers. The studies also agree that there are differences between males and females in the perception and evaluation of violent behavior. Furthermore, the sex of the participants in a violent situation is crucial and can produce different results for the variables being measured [42]. In this vein, the study that is presented here is based principally on some of the studies cited previously, but it extends the research and makes some modifications.

Most of the above studies examined the perceptions of aggressive interactions, but to the researcher's knowledge, no study has included the study of predictions of aggression involving adolescents, or the study of types of aggression other than physical aggression. The studies described above 
examined adult perceptions of aggressive interactions between adults or very young children engaging in real-life aggression, and the effects of the sex of the aggressor, target, and observer. But fewer studies have examined adolescents' predictions of aggression involving adolescents. Therefore, same-age observers may have different predictions regarding aggression than different-age observers, as they are likely to experience and be familiar with very different types of aggression [34]. Therefore, I propose that adolescent observers may have different predictions regarding situations of aggression than adult observers do.

Moreover, previous research has focused mainly on studying the perceptions of physical aggression, without considering other types of aggression. Only a few studies have examined same-age perceptions of adolescent indirect aggression. Galen and Underwood [65] examined same-age perceptions of adolescent indirect aggression; however, they only showed examples of indirect aggression by girls, so it is not known how adolescents predict male indirect aggression relative to female indirect aggression, or other types of aggression. Coyne et al. [66] studied sex differences in adolescent perceptions of aggression, but they studied the perceptions of indirect aggression only through the medium of television, and they did not examine predictions of verbal or physical aggression. Therefore, the present study was designed to explore predictions of three types of aggression: physical, verbal, and indirect aggression.

Lastly, the researcher extended the situations where violence can take place, using situations in which adolescents could easily identify themselves. These situations were scenarios of aggression that adolescents had documented in a pilot study [42]. The adolescents had been part of the situations, directly or indirectly, or had heard of the situations from others. In this way, both situations of aggression within the family and situations of aggression between equals in places of leisure are included.

Therefore, the aim of this study is to establish whether Spanish adolescent boys and girls differ in their predictions of the behavioral patterns of male and female aggressors as a function of the sex of the target in different hypothetical scenarios of aggression. More specifically, the study examines the adolescents' predictions of the behavioral patterns of the aggressor in hypothetical situations of physical, verbal, and indirect aggression enacted by peers and adults, as well as sex differences in these perceptions.

On the basis of past research and the theoretical considerations discussed earlier, hypotheses were formulated concerning how adolescents would predict the type of aggression that a person would use in a scenario of aggression, as a function of the sex of the aggressor and the target. It was predicted that when the aggressor was a male, the participants would predict that he would use direct (physical and verbal) aggression more than when the aggressor was a female. Since previous research supports the view that indirect aggression is more typical of females [e.g., 1, 26, 29, 30-33, $35,38,39]$, and that more experience with a certain behavior will enhance stereotypical beliefs about sex differences in aggressive behavior [43], it was predicted that participants would predict that females would use indirect aggression more often than males.
Therefore, for two variables - sex of the aggressor and sex of the target-it was predicted that when the aggressor and the target were both males, the adolescents would predict that the aggressor would use more physical and verbal aggression than when the aggressor and target were both females, in which case the aggressor would be predicted to use more indirect aggression. Also, it was hypothesized that a male aggressor would be predicted to use physical and verbal aggression more than a female in all the scenarios of aggression. Furthermore, following the trend revealed in previous research, it was predicted that females would predict more aggression in a wider range of situations than would males.

\section{METHODOLOGY}

\section{Participants}

The participants were 653 adolescents (49\% boys and $51 \%$ girls) attending classes at four high schools in Madrid, Spain. Their ages ranged from 14 to 18 , with a mean of 15.54 years $(S D=1.01)$ (girls: $M=15.56, S D=1.05$; boys: $M=15.51, S D=0.97)$. The type of education of the high schools and the socioeconomic status of the area were the following: a private-religious high school in a medium-low socioeconomic area (28.3\%), a private-religious high school in a medium-high socioeconomic area $(24.2 \%)$, a publicnonreligious high school in a medium-low socioeconomic area $(31.1 \%)$ and a public- nonreligious high school in a medium-high socioeconomic area (16.4\%). In each high school, five classes from each grade were randomly selected for inclusion in the study.

\section{Instrument}

The researcher designed an instrument with four scenarios describing an episode of aggression in a valid representation of a real-life situation. In a previous pilot study $(\mathrm{N}=60)$, different scenarios of aggression were used with an openanswer questionnaire. But in a focus group during this pilot study, it was detected that the adolescents were unfamiliar with some of the scenarios of aggression, and not enough information could be obtained. Also, the adolescents told the researcher that the scenarios were unreal and strange for them. So they were asked to talk about situations involving aggression in which they had been involved directly or indirectly, or aggressive situations that they had heard about. It was then decided to select this information about aggressive situations that were more familiar to the adolescents. Afterwards, four short scenarios were specifically created for the current study with respect to the experimental conditions and the two independent variables (sex of aggressor and sex of target) being studied.

Respondents heard a description of each scenario, in which two individuals became involved in a dispute and one of them ("the aggressor") started acting aggressively toward the other ("the target"). The scenario was kept as brief and neutral as possible in order to adapt it to the various malefemale combinations and to real situations in which adolescents could be involved. The scenarios were left unfinished to allow the subjects to imagine what would happen afterward. The sex of the aggressor and the target were manipulated in each scenario in a $2 \times 2$ design, totaling four ver- 
sions. There were two different scenarios describing an episode of aggression; each one was used twice with the only difference being the sex of the aggressor and of the target. Specifically, the scenarios were as follows: In the first situation, a male is aggressive toward a female in a domestic context. The second scenario is the same as the previous one, except that a female starts an aggressive behavior toward a male in a domestic context. The third and fourth scenarios of aggression take place between peers: a male adolescent starts an aggressive behavior toward another male adolescent, and a female adolescent starts an aggressive behavior toward another female adolescent, respectively. In these cases the conflicts take place at a bar rather than in a domestic context.

Each of the four scenarios was followed by one question with twelve items (four for each type of aggression: physical, verbal, and indirect) in which the participants were asked to answer what they thought the person who had started the dispute would do next. The statement was the following: "What do you think Josephine (in each scenario the name of the aggressor changes) will do in this situation? Participants rated responses on a 5-point scale ranging from 0 (very unlikely) to 4 (very likely).

The answers to these questions from the participants allowed the assessment of three dependent variables: the prediction of physical, verbal, and indirect aggression. To explore the adolescents' predictions of aggression, twelve items from the Direct \& Indirect Aggression Scales (DIAS) by Björkqvist et al. [67] were used in each scenario. According to the original Direct and Indirect Aggression Scale (DIAS), which allows the measurement of direct (physical and verbal) and indirect (social manipulation) strategies of aggression, in each scenario four specific items were used to measure physical aggression (hits the other, kicks the other, shoves the other, takes things from the other), four items were used to measure verbal aggression (yells at or argues with the other, insults the other, says he/she is going to hurt the other, teases the other) and four items were used to measure indirect aggression (plans secretly to cause trouble for the other, ignores the other, says bad things behind the other's back, criticizes the other's hair or clothing). Before using these items, the researcher had confirmed the validity and applicability of the DIAS in an earlier study [15] in which a Spanish version of the DIAS was used to measure aggressive behavior using self-estimations in the same sample of Spanish adolescents as used in the current study. In this sample the internal consistency of the three factors (physical, verbal, and indirect aggression), evaluated by the alpha coefficient, was .92 [15].

\section{Procedure}

The questionnaire data were collected individually by the researcher during school hours in groups of approximately 30 students, and participation was voluntary. Participants were instructed not to write their names anywhere on the questionnaire so that their data would remain anonymous. The application of the instrument was counterbalanced in two sessions to control for a possible order effect. In the first test session, roughly $50 \%$ of the subjects completed two of the four scenarios while the other half completed the other two. In the second test session, which took place after a break, the subjects completed the two scenarios that had not been completed previously.

\section{RESULTS}

The mean and standard deviation scores for males and females on the three dependent variables measured for each experimental condition are presented in Table 1. The scores nearest 0 imply that the adolescent did not predict that the aggressor would use this type of aggression, whereas the scores nearest 4 mean that the adolescent predicted that the aggressor would very likely use this type of aggression.

In order to assess the effects of the manipulations, the scenarios were analyzed with a 2 (sex of aggressor [male, female]) by 2 (sex of target [male, female]) multifactorial repeated measures design with the subjects' sex as an intergroup factor. The researcher obtained the main effect of the two independent variables (sex of aggressor and sex of target) and the interaction between these variables (sex of aggressor $\mathrm{x}$ sex of target) and also the interaction with these and the sex of the subjects. The differences in the main simple effects were analyzed with confidence intervals previously corrected by the Bonferroni procedure. The F-values, degrees of freedom, and significance of the differences for each kind of aggression are presented in Table $\mathbf{2}$.

\section{Physical aggression}

Results showed a significant main effect of the sex of the aggressor on the prediction of physical aggression, which indicates that when the aggressor was a male, the adolescents predicted that he would use physical aggression more than when the aggressor was a female. However, there was no significant interaction between the sex of the aggressor and the sex of the subject variables in the prediction of physical aggression (see Table 2).

There was no significant main effect of the sex of the target on the prediction of physical aggression, but there was a significant interaction between the sex of the target and the sex of the subject variables, with male subjects rating physical aggression higher than female subjects when the target was a male (males: $M=1.76, S D=.05$; females: $M=1.55, S D=.05)$.

Furthermore, results showed a significant interaction between the sex of the aggressor and the sex of the target: when the aggressor and the target were males, the adolescents predicted that the aggressor would use physical aggression. However, there was no significant interaction with the sex of the subject variable. These results indicate that the adolescents more easily predicted the use of physical aggression when the aggressor and the target were both males than when the target was a female. On the other hand, when the aggressor was a female and the target was a female, the adolescents predicted that the aggressor would use physical aggression more than when the target was a male.

If we compare the mean scores in all the scenarios (see Table 1) we can observe in which of them the adolescents more readily predicted the use of physical aggression. For the scenarios, the subjects predicted that the aggressor would use physical aggression in the following order, from highest to lowest likelihood: $3,4,1$, and 2 . These results show that 
Table 1. Predictions Made by Male and Female Respondents Regarding what Kind of Aggression the Aggressor Would Resort to Next

\begin{tabular}{|c|c|c|c|c|c|c|c|c|}
\hline & \multirow[t]{3}{*}{ Scenarios } & \multirow[b]{3}{*}{ SEX } & \multirow{2}{*}{\multicolumn{2}{|c|}{$\begin{array}{c}\begin{array}{c}\text { Physical } \\
\text { Aggression }\end{array} \\
\begin{array}{c}\text { N= 561 } \\
\text { Males N= 276 }\end{array} \\
\text { Females N= 285 }\end{array}$}} & \multirow{2}{*}{\multicolumn{2}{|c|}{$\begin{array}{c}\begin{array}{c}\text { Verbal } \\
\text { Aggression }\end{array} \\
\mathrm{N}=\mathbf{5 5 3} \\
\text { Males } \mathrm{N}=\mathbf{2 6 9} \\
\text { Females } \mathrm{N}=\mathbf{2 8 4}\end{array}$}} & \multirow{2}{*}{\multicolumn{2}{|c|}{$\begin{array}{c}\begin{array}{c}\text { Indirect } \\
\text { Aggression }\end{array} \\
\mathbf{N}=\mathbf{5 5 8} \\
\text { Males N= 272 } \\
\text { Females N= 286 }\end{array}$}} \\
\hline & & & & & & & & \\
\hline & & & Mean & $S D$ & Mean & $S D$ & Mean & $S D$ \\
\hline \multirow{4}{*}{$\begin{array}{c}\text { Domestic } \\
\text { setting }\end{array}$} & \multirow{2}{*}{$\begin{array}{l}\text { 1. A male is aggressive toward a female MALE- } \\
\text { FEMALE }\end{array}$} & FEMALES & 1.51 & 1.05 & 3.04 & 0.94 & 1.71 & 1.07 \\
\hline & & TOTAL & 1.48 & 1.09 & 2.94 & 0.95 & 1.69 & 1.05 \\
\hline & \multirow{2}{*}{$\begin{array}{l}\text { 2. A female is aggressive toward a male FE- } \\
\text { MALE-MALE }\end{array}$} & MALES & 1.22 & 1.06 & 2.65 & 0.88 & 1.69 & 1.06 \\
\hline & & TOTAL & 0.64 & 0.61 & 2.39 & 0.91 & 2.23 & 1.05 \\
\hline \multirow{6}{*}{$\begin{array}{l}\text { Adolescents } \\
\text { in a bar }\end{array}$} & \multirow{3}{*}{$\begin{array}{l}\text { 3. A male is aggressive toward another male } \\
\text { MALE-MALE }\end{array}$} & MALES & 2.30 & 1.01 & 3.34 & 0.75 & 2.25 & 0.91 \\
\hline & & FEMALES & 2.13 & 1.01 & 3.36 & 0.76 & 2.09 & 0.95 \\
\hline & & TOTAL & 2.22 & 1.01 & 3.35 & 0.76 & 2.17 & 0.93 \\
\hline & \multirow{3}{*}{$\begin{array}{l}\text { 4. A female is aggressive toward another female } \\
\text { FEMALE-FEMALE }\end{array}$} & MALES & 1.91 & 1.09 & 3.07 & 0.86 & 2.43 & 0.93 \\
\hline & & FEMALES & 1.90 & 1.04 & 3.20 & 0.87 & 2.47 & 0.98 \\
\hline & & TOTAL & 1.90 & 1.07 & 3.13 & 0.87 & 2.45 & 0.95 \\
\hline
\end{tabular}

Table 2. Interaction Between the Three Independent Variables and the Sex of the Subject on the Prediction of Physical, Verbal and Indirect Aggression

\begin{tabular}{|c|c|c|c|c|c|c|c|c|c|}
\hline & \multicolumn{3}{|c|}{ Physical Aggresion } & \multicolumn{3}{|c|}{ Verbal Aggression } & \multicolumn{3}{|c|}{ Indirect Aggression } \\
\hline & $\mathbf{F}$ & D.f. & $\mathbf{P}$ & $\mathbf{F}$ & D.f. & $\mathbf{P}$ & $\mathbf{F}$ & D.f. & $\mathbf{P}$ \\
\hline Sex of Aggresor & 156.04 & 559 & $.000 * * *$ & 155.21 & 551 & $.000 * * *$ & 15.42 & 556 & $.000 * * *$ \\
\hline Sex of Aggressor X Sex of Subject & 1.44 & 559 & .229 & 2.36 & 551 & .125 & .04 & 556 & .832 \\
\hline Sex of Target & 1.07 & 559 & .300 & 3.43 & 551 & .065 & 24.89 & 556 & $.000 * * *$ \\
\hline Sex of Target X Sex of Subject & 10.76 & 559 & $.001 * * *$ & 8.78 & 551 & $.003 * *$ & 6.86 & 556 & $.009 * *$ \\
\hline Sex of Aggressor X Sex of Target & 468.60 & 559 & $.000 * * *$ & 261.59 & 551 & $.000 * * *$ & 330.34 & 556 & $.000 * * *$ \\
\hline Sex of Aggressor X Sex of target X Sex of Subject & .03 & 559 & .849 & .06 & 551 & .800 & .02 & 556 & .867 \\
\hline
\end{tabular}

the situations in which subjects predicted that the aggressor would use more physical aggression were when a male adolescent was aggressive toward another male adolescent in a bar and when a female adolescent was aggressive toward another female adolescent in a bar. These scores were followed by the scenarios in which a male was aggressive toward a female and a female was aggressive toward a male in a domestic setting. The scenario in which the subjects predicted that the aggressor would use less physical aggression was that in which a female was aggressive toward a male. As we can observe, in each pair of scenarios the adolescents more readily predicted the use of physical aggression when it was used by a male: first, when the aggression took place between peers (two male adolescents), and finally in a domestic context. Also, results show that male subjects scored higher than females in the prediction of physical aggression in experimental conditions 2, 3 and 4, while females scored higher than males in experimental condition 1. 


\section{Verbal Aggression}

Results (see Table 2) showed a significant main effect of the sex of the aggressor on the prediction of verbal aggression. These results indicate that when the aggressor was a male, the adolescents predicted that the aggressor would use verbal aggression more than when the aggressor was a female. However, there was no significant interaction between the sex of the subject and sex of the aggressor variables.

There was a significant interaction between the sex of the target and the sex of the subject variables, with females rating verbal aggression higher than males when the target was a female (males: $M=2.95, S D=.05$; females: $M=3.11$, $S D=.04)$.

Moreover, there was a significant interaction between the two independent variables, sex of the aggressors $\mathrm{x}$ sex of the target, but there was no significant interaction between the two independent variables and the sex of the subject as an intergroup factor. These results indicate that the adolescents predicted the use of verbal aggression more when the aggressor and the target were both males than when the aggressor was a female and the target was a male. On the other hand, when the aggressor was a female and the target was a female, the adolescents predicted that the aggressor would use more verbal aggression than when the aggressor was a male and the target a female.

If we compare the mean scores in all the scenarios (see Table 1) we can observe in which of them the adolescents more readily predicted the use of verbal aggression. The prediction of verbal aggression, from highest to lowest, was ordered as follows: experimental conditions $3,4,1$, and 2 . These results show that the situations in which subjects predicted that the aggressor would use more verbal aggression were when a male adolescent was aggressive toward another male adolescent in a bar and when a female adolescent was aggressive toward another female adolescent in a bar. These scores were followed by the situations in which a male was aggressive toward a female and a female was aggressive toward a male in a domestic setting. As we can observe, in each pair of scenarios the adolescents more readily predicted the use of verbal aggression when it was used by a male: first, when the aggression took place between peers (two male adolescents) and second, in a domestic context. Also, results show that male subjects scored higher than females in the prediction of verbal aggression in experimental condition 2 , while females scored higher than males in experimental conditions 1,3 and 4 .

\section{Indirect Aggression}

Results showed a significant main effect of the sex of the aggressor and the sex of the target in the prediction of indirect aggression. These results indicate that when the aggressor was a female and the target a female, the adolescents predicted that the aggressor would use indirect aggression more than when the aggressor was a male and the target was a male (see Table 2).

Also, there was a significant interaction between the sex of the subject and the sex of the target variables, with female subjects rating aggression higher than males when the target was a female (males: $M=2.04, S D=.05$; females: $M=2.08$,
$S D=.05)$. However, there was no significant interaction between the sex of the subject and the sex of the aggressor variables.

Furthermore, results showed a significant interaction between the sex of the aggressor and the sex of the target, which indicates that when the aggressor and the target were both females, the adolescents predicted that the aggressor would use indirect aggression more than when the target was a male. However, there was no significant interaction with the sex of the subject variable.

If we compare the mean scores in all the scenarios (see Table 1), we can observe in which of them the adolescents more readily predicted the use of indirect aggression. The prediction of indirect aggression is ordered as follows, from highest to lowest: experimental conditions $4,3,1$, and 2 . These results show that the situations in which adolescents more readily predicted that the aggressor would use indirect aggression were when the aggression took place between two adolescent females, followed by the aggression between two adolescent males. These scores were followed by the situations in which a male was aggressive toward a female and a female was aggressive toward a male in a domestic setting. As we can observe, in each pair of scenarios the adolescents more easily predicted the use of indirect aggression when it was used by a female, but not in the domestic context, where adolescents predicted that males would use more indirect aggression than females. Also, results show that male subjects scored higher than females in the prediction of indirect aggression in experimental conditions 2 and 3, while females scored higher than males in experimental conditions 1 and 4.

\section{DISCUSSION}

Previous research has demonstrated that aggressive situations between men and women are perceived and evaluated differently by observers, and that there are sex differences in these perceptions. Moreover, the sex of the aggressor, the sex of the target, and the type of interactions between the protagonists who are involved in an aggressive situation are crucial and can produce different results in perceptions and evaluations of the aggressive situations. Most studies have focused mainly on studying perceptions of physical aggression without considering predictions of this type of aggression. In addition, these studies have not often explored other types of aggression, and they are devoid of same-age perceptions of adolescents' aggression. Therefore, the purpose of the present study was to examine adolescents' predictions of physical, verbal, and indirect aggression in hypothetical scenarios of aggression enacted by peers and adults, as well as sexual differences concerning this variable. Furthermore, the situations in which aggression can take place were extended to check if the predictions of aggression were related to the sex of the aggressor and of the target.

Results from the present study confirm sex differences in predictions of aggression and support some of the predictions formulated. The results show consistency with the hypothesis of the study and with previous research. It was predicted that when the aggressor was a male, the participants would predict that he would use direct aggression (physical and verbal) more than when the aggressor was a female; the 
results confirmed this. Since previous research supports the view that indirect aggression is more typical of females [1, $26,28-33,35-39]$, and more experience with a certain behavior will enhance stereotypical beliefs between sex differences in aggressive behavior [43], it was predicted that females would be predicted to use indirect aggression more often than males, and as expected, results confirm this hypothesis; when the aggressor was a female, the adolescents predicted that the aggressor would use indirect aggression more than when the aggressor was a male.

A significant interaction was found between the sex of the aggressor $\mathrm{x}$ the sex of the target. For these two variables, it was predicted that when the aggressor and the target were both males, the adolescents would predict that the aggressor would use more physical and verbal aggression than when the aggressor and target were both females, in which the subjects would predict that they would use indirect aggression more. The results confirmed the hypothesis.

In the four scenarios of aggression, the subjects predicted that the aggressor would use more physical and verbal aggression in the scenarios between peers. As for indirect aggression, subjects predicted that the aggressor would use indirect aggression when the scenario took place between two adolescent females. Furthermore, it was found that in each pair of scenarios of aggression, the adolescents more readily predicted the use of physical and verbal aggression when it was used by a male: first, when the aggression took place between peers (two male adolescents), and then in a domestic context. So the hypothesis (male aggressor would be predicted to use physical and verbal aggression more in all the scenarios of aggression) was supported. Nevertheless, it was quite opposite for indirect aggression, with the adolescents predicting that the aggressor would use indirect aggression when the aggressor was a female except in the domestic context, in which adolescents predicted that males would use more indirect aggression than females. In the domestic context, adolescents predicted that males would use more physical, verbal, and indirect aggression than would females. Unfortunately, in Spain the number of females killed by their husbands/partners increases every day, and this could explain adolescents' perceptions of aggression in the domestic context. Another troublesome trend is that violence among adolescents of the same sex, both male and female, is increasing in Spanish society, and there is a lot of work still to do on this issue, since most work has been done to prevent violence between members of the opposite sex.

Moreover, following the trend revealed in previous research, $[50,51,55]$ it was predicted that females would predict aggression in a wider range of situations than males would, but the results did not totally confirm this hypothesis. A number of differences were found between male and female participants in terms of how they predicted the aggression depicted in the scenario. When we checked sex differences in the predictions of physical, verbal, and indirect aggression, there was no significant interaction between the sex of the aggressor $\mathrm{x}$ the sex of the target and the sex of the subject; a significant interaction was found only with the variables separated. In contrast with previous research [e.g., $64,65]$, males predicted more use of physical aggression than females did when the target was a male. And females predicted more verbal and indirect aggression when the target was a female. For indirect aggression, females predicted more aggression than males in the situations where a male was aggressive toward a female in a domestic context and a female adolescent was aggressive toward another female adolescent in a bar, while males predicted more aggression than females in the other two experimental conditions. So, on average, males anticipated the use of physical aggression in a wider range of situations than did females.

Prior work that has found that males are in general physically and verbally more aggressive than females [16, 18-23] and that females prefer to use indirect aggression $[1,3,6-8$, 26, 28-39] are consistent with these results, since they correspond with the principles of social cognition in the study of the perception and interpretation of aggression, as well as with research on gender stereotypes that has shown that males are perceived to be more aggressive in general than females, with males being perceived to be more physically aggressive [46-51, 55, 56, 59] and females being perceived to be more indirectly aggressive [57-60]. The current study shows that the stereotype that men are more physically and verbally aggressive and women are more likely to engage in indirect forms of indirect aggression may actually exist and is in concordance with many studies that have shown indirect aggression to be more acceptable in female social groups.

It is interesting to observe the types of aggression that the adolescents predicted in this study; These findings could be related to the increasing evidence of aggression by Spanish female adolescents in the last several years. The results of the current study are related to another study involving perceptions of aggression conducted with the same sample of adolescents, in which it was found that it was precisely in situations of violence between two adolescent females in a leisure situation that violence was most justified by subjects [68], the target female being considered guilty of provoking the incident [69]. Also, the scenario in which the subjects assessed the target worst was that in which a female adolescent was aggressive toward another female adolescent in a bar [42]. It seems that the sexist stereotype that women have had as being guilty of provoking the violent situation has not been completely overcome, so adolescents tend to assess the female target worse and justify more the use of violence between girls; this violence seems "acceptable" by adolescents. This finding might explain the greater prediction of verbal and indirect aggression by female adolescents in this study. When adolescents view physical and verbal aggression between boy peers and toward a female in a domestic context, and when adolescents view indirect aggression between girl peers and toward a female in a domestic context, this aggression seems normal for the adolescents. This highlights the importance of studying different forms of aggression in boy and girl peer groups, as adolescents may perceive aggression to be as common in peer groups as in a domestic setting, and become insensitive to this aggression.

Of course, this study has limitations. In the scenarios of aggression used in the study, the behavior of the aggressor that was used to prime the subjects' predictions of what would happen next was only verbally aggressive. Therefore, it would be interesting in future studies to use scenarios in 
which other forms of aggression take place to prime subjects' predictions of what will happen next. Also, the combinations of sex of aggressor and sex of target should be expanded in order to analyze the predictions of adolescent violence between two adolescents of different sexes. Variables other than those already studied could be included, such as the social status or age of the persons in the scenarios. Thus it would be enriching to include more scenarios of aggression (e.g., situations of aggression between adolescents in school, between acquaintances and strangers, in organizational contexts, young dating relationships, between teachers and students, and so forth), other sex combinations, and other relationships between aggressor and target, and to use only scenarios in which at least one of the protagonists is an adolescent or combinations with different ages and sexes.

Finally, it would be interesting to include predictor variables that could influence the perceptions and representations of the adolescents when observing situations of aggression. As different forms of aggression by boys and girls are perceived differently, it will be important to establish how different types of aggressive behaviour in the scenarios may affect subjects' predictions of subsequent aggressive actions. For further study, it would be interesting to use peer estimations in this population to check if these perceptions of aggression in female adolescents reflect how females really use aggression.

\section{CONCLUSION}

To conclude, these findings are discussed in terms of their relevance for the design of new prevention and intervention programs against the use of aggression, using different situations where aggression takes place, and also for the inclusion of activities in these programs to teach adolescents how to resolve conflicts using non-violent alternatives. It is important to draw distinctions between styles of aggression and to study the representations of aggression, including indirect aggression and other independent variables that could be influencing predictions of aggression. Also, it is necessary to carry out programs to prevent the use of verbal aggression, since this type of aggression is very prevalent. Finally, the results of this study warn of the necessity to carry out interventions that permit the overcoming of sexist stereotypes toward women and men of any age and in all environments.

\section{CONFLICTS OF INTEREST}

None Declared

\section{ACKNOWLEDGEMENTS}

This research was conducted as part of a doctoral dissertation by the author at the Complutense University of Madrid, supported by a scholarship from the Spanish Ministry of Science and Technology.

\section{REFERENCES}

[1] Björkqvist K, Österman K, Kaukiainen A. The development of direct and indirect aggressive strategies in males and females. In: Björkqvist K, Niemelä P, Ed. Of mice and women: Aspects of female aggression, San Diego, CA: Academic Press 1992; pp. 51-64.
[2] Crick NR, Grotpeter J. Relational aggression, gender, and socialpsychological adjustment. Child Dev 1995; 66: 710-722

[3] Lagerspetz KMJ, Björkqvist K, Peltonen T. Is indirect aggression typical of females? Gender differences in aggressiveness in 11- to 12- year old children. Aggr Behav 1988; 14: 403-414.

[4] Salmivalli C, Kaukiainen A, Lagerspetz K. Aggression and sociometric status among peers: do gender and type of aggression matter. Sandinavian J Psychol 2000; 41: 17-24.

[5] Underwood MK. Social aggression among girls. New York: Guilford Press 2003.

[6] Archer J. Sex differences in aggression in real-world settings: A meta-analytic review. Rev Gen Psychol 2004; 8: 291-332.

[7] Archer J. Sex differences in aggression between heterosexual partners: A meta-analytic review. Psychol Bull 2000; 126: 651-680.

[8] Archer J, Coyne SM. An integrated review of indirect, relational, and social aggression.Pers Soc Psychol Rev 2005; 9: 212-230.

[9] Baron RA, Richardson DR. Aggression. New York: Plenum Press 1994.

[10] Benson PL. The troubled journey: A portrait of 6th-12th graders. Minneapolis, MN: Search Institute 1993.

[11] Bettencourt BA, Miller N. Gender differences in aggression as a function of provocation: A meta-analysis. Psychol Bull 1996; 119: $422-447$.

[12] Björkqvist K, Niemelä P. New trends in the study of female aggression. In: Björkqvist K, Niemelä P, Ed. Of mice and women: Aspects of female aggression, San Diego, CA: Academic Press 1992; pp. 3-16.

[13] Eagly AH, Wood WE. Explaining sex differences in social behavior: A meta-analytic perspective. Per Soc Psychol Bull 1991; 17: 306-315.

[14] Maccoby EE, Jacklin CN. Sex differences in aggression: A rejoinder and reprise. Child Devel 1980; 51: 964-980.

[15] Toldos MP. Sex and age differences in self-estimated physical, verbal and indirect aggression in Spanish adolescents.Aggr Behav 2005; 31: 13-23.

[16] Eagly AH, Steffen VJ. Gender and aggressive behavior: A metaanalytic review of the social psychological literature. Psychol Bull 1986; 100: 309-330.

[17] Hammock GS, Richardson DR. Predictors of aggressive behavior. AggrBehav 1992; 18: 219-229.

[18] Hyde JS. How large are gender differences in aggression?: A development meta-analysis. Dev Psychol 1984; 20: 722-736.

[19] Berkowitz L. Aggression: Its causes, consequences and control. Philadelphia: Temple University Press 1993.

[20] Harris MB. Sex, race, and experiences of aggression.AggrBehav 1992; 18: 201-217.

[21] Olweus D. Bullying or peer abuse at school: Facts and intervention. Curr Direc Psychol Sci 1995; 4: 196-200.

[22] Archer J, Holloway R, McLoughlin K. Self-reported physical aggression among young men. AggBehav1995; 21: 325-342.

[23] Buss AH, Perry M. The aggression questionnaire. J Pers Soc Psychol 1992; 63: 452-459.

[24] Frodi A, Macaulay J, Thome PR. Are women always less aggressive than men? A review of the experimental literature.Psychol Bull 1977; 84: 634-660.

[25] Maccoby EE, Jacklin CN. The psychology of sex differences. Stanford, CA: Stanford University Press 1974.

[26] Björkqvist K, Lagerspetz KMJ, Kaukiainen A. Do girls manipulate and boys fight?. Developmental trends regarding direct and indirect aggression.Aggr Behav 1992; 18: 117-127.

[27] Salmivalli C, Kaukiainen A, Lagerspetz K. Aggression and sociometric status among peers: Do gender and type of aggression matter?.Scandinavian J of Psychol 2000; 41: 17-24.

[28] Archer J, Pearson NA, Westerman KE. Aggressive behavior of children aged 6-11: gender differences and their magnitude. Br J Soc Psychol 1988; 27: 371-384.

[29] Björkqvist K. Sex differences in physical, verbal, and indirect aggression: A review of recent research. Sex Roles 1994; 30: 177-188.

[30] Björkqvist K, Österman K, Lagerspetz, KM. Sex differences in covert aggression among adults. AggrBehav 1994; 20: 27-33.

[31] Campbell A. Staying alive: Evolution, culture, and women's intrasexual aggression. Behav Brain Sci 1999; 22: 203-252.

[32] Campbell A, Muncer S, Gorman B. Sex and social representations of aggression: A communal-agentic analysis. Aggr Behav 1993; 19: $125-135$. 
[33] Capaldi DM, Crosby L. Observed and reported psychological and physical aggression in young at risk couples. Soc Dev 1997; 6: 184-206.

[34] Lagerspetz KMJ, Björkqvist K. Indirect aggression in boys and girls. In: Huesman LR, Ed.Aggressive behavior: current perspectives, New York: Plenum Publishing Corporation 1994; pp. 131-150.

[35] Österman K, Björkqvist K, Lagerspetz KMJ, Kaukiainen A, Huesmann LR, Fraczek A. Peer and self-estimated aggression and victimization in 8-year-old children from five ethnic groups. AggrBehav 1994; 20: 411-428.

[36] Österman K, Björkqvist K, Lagerspetz KMJ, Landau SF, Fraczek A, Pastorelli C. Sex differences in styles of conflict resolution: a developmental and cross-cultural study with data from Finland, Israel, Italy, and Poland. In: Fry DP, Björkqvist K, Ed. Cultural variation in conflict resolution: alternatives to violence, New York: Lawrence Erlbaum 1997; pp. 185-197.

[37] Österman K, Björkqvist K, Lagerspetz KMJ, Kaukiainen A, Landau S, Fraczek A, Caprata GV. Cross-Cultural evidence of female indirect aggression. Aggr Behav 1998; 24: 1-8.

[38] Richardson RB, Green L. Social sanction and threat explanations of gender effects on direct and indirect aggression. Aggr Behav 1999; 25: 425-434.

[39] White JW, Kowalski RM. Deconstructing the myth of the nonaggressive woman. Psychol Women Q 1994; 18: 487-508.

[40] Eagly AH. Sex differences in social behavior: A social roles interpretation. Hillsdale, NJ: Erlbaum 1987.

[41] Toldos MP. Los jóvenes y la violencia: Creencias y actitudes ante la violencia familiar y la igualdad entre varones y mujeres. Editorial Académica Española 2011.

[42] Toldos MP. Effects of sex and status of target and aggressor on adolescents' assessment of the target in scenarios of aggression. In:Renshaw A, Suarez E, Ed. Violent crime and prisons: Population, health conditions and recidivism, N.York: Nova Science Publishers 2010; pp. 199-212

[43] Condry JC, Ross DF. Sex and aggression: The influence of gender labels on the perception of aggression in children. Child Dev 1985; 56: $225-233$

[44] Ostrov JM, Crick NR, Keating CF. Gender-biased perceptions of preschoolers' behavior: How much is aggression and prosocial behavior in the eye of the beholder?. Sex Roles 2005; 52: 393-398.

[45] Susser SA, Keating CF. Adult sex role orientation and perceptions of aggressive interactions between girls and boys. Sex Roles 1990; 23: $147-155$

[46] Broverman IK, Vogel SR, Broverman DM, Clarkson FE, Rosenkrantz PA. Sex role stereotypes: A current appraisal. J Soc Issues 1972; 28: 59-78.

[47] Ruble TL. Sex stereotypes: Issues of change in the 1970s. Sex Roles 1983; 9: 397-402.

[48] Spence JT, Helmreich RL. Masculinity and femininity.Their Psychological dimensions, correlates and antecedents. Austin: University of Texas Press 1978.

[49] Gerber G. Gender stereotypes and power: perceptions of the roles in violent marriages. Sex Roles 1991; 24: 439-457.

[50] Harris MB, Knight-Bohnhoff K. Gender and aggression: I. Perceptions of aggression. Sex Roles 1996; 35: 1-26.
[51] De Meijer M. The attribution of aggression and grief to body movements: The effect of sex-stereotypes. European J Soc Psychol 1991; 21: 249-259.

[52] Hilton NZ, Harris GT, Rice ME. Adolescents' perceptions of the seriousness of sexual aggression: Influence of gender, traditional attitudes, and self-reported experience. Sex Abuse 2003; 15: 201-214.

[53] Steward-Williams S. Gender, the perception of aggression, and the overestimation of gender bias. Sex Roles 2002; 46: 177-189.

[54] Marks MA, Nelson ES. Sexual harassment on campus: Effects of professor gender on perception of sexually harassing behaviors. Sex Roles 1993; 28: 207-217.

[55] Herzberger SD, Tennen H. "Snips and snails and puppy dog tails": Gender of agent, recipient, and observer as determinants of perceptions of discipline. Sex Roles 1985; 12: 853-865.

[56] Howe A, Herzberger S, Tennen H. The influence of personal history of abuse and gender on clinicians' judgments of child abuse. J Fam Viol 1988; 3: 105-119.

[57] Lutz IM. Aggressive girls at school.AggrBehav 1999; 25: 27-28.

[58] Beth RC. High school teachers' perceptions of adolescent female social aggression.University of Hartford 2006.

[59] Sears HA, Byers ES, Whelan JJ, Saint-Pierre M. If it hurts you, then it is not a joke: Adolescents' ideas about girls' and boys' use and experience of abusive behavior in dating relationships. J Interp Viol 2006; 21: 1191-1207.

[60] Basow SA, Cahill KF, Phelan JE, Longshore K, McGillicuddyDeLisi A. Perceptions of relational and physical aggression among college students: Effects of gender of perpetrator, target, and perceiver. PsycholWome Q 2007; 31: 85-95.

[61] Lyons JA, Serbin LA.Observer bias in scoring boys' and girl's aggression. Sex Roles 1986; 14: 301-313.

[62] García L, Milano L, Quijano A. Perceptions of coercive sexual behavior by males and females. Sex Roles 1989; 21: 569-577.

[63] Koski PR, Mangold WD. Gender effects in attitudes about family violence. J Fam Viol 1988; 3: 225-237.

[64] Harris MB, Cook CA. Attributions about spouse abuse: It matters whom the batterers and victims are. Sex Roles 1994; 29: 629-644.

[65] Galen BR, Underwood MK. A developmental investigation of social aggression among children. Dev Psychol 1997; 33: 589-600.

[66] Coyne SM, Archer J, Eslea M, Liechty T. Adolescent perceptions of indirect forms of relational aggression: Sex of perpetrator effects. Aggr Behav2008; 34: 577-583.

[67] Björkqvist K, Lagerspetz KMJ, Österman K. The Direct and Indirect Aggression Scales (DIAS). Vasa, Findland: AboAcademi University, Department of Social Sciences 1992.

[68] Toldos MP. Effects of sex and status of target and aggressor on adolescents' justification of aggression. In: Österman K, Björkqvist $\mathrm{K}$, Ed. Contemporary research on aggression, AboAkademy University, Vasa, Finland 2006; pp. 64-68.

[69] Toldos MP. Adolescencia, violencia y género. PhD. diss., Dept. of Psychology, Universidad Complutense de Madrid 2002.

Received: January 01, 2011

Revised: May 01, 2011

Accepted: May 02, 2011

(C) María de la Paz Toldos Romero; Licensee Bentham Open.

This is an open access article licensed under the terms of the Creative Commons Attribution Non-Commercial License (http://creativecommons.org/licenses/by-nc/3.0/) which permits unrestricted, non-commercial use, distribution and reproduction in any medium, provided the work is properly cited. 